\title{
The Lauge-Hansen Classification for Ankle Fractures: Is it Relevant in 2017?
}

\author{
${ }^{1}$ Mandeep S Dhillon, ${ }^{2}$ Lokesh Kumar, ${ }^{3}$ Siddhartha Sharma, ${ }^{4}$ Nikhil Mehta
}

\begin{abstract}
Despite being one of the commonest fractures, classifications of ankle injuries are still debated, with modern surgeons decrying the use of the so-called antiquated system based on injury mechanisms. Despite glaring lacunae, especially with lack of reproducibility using modern methods, and an understanding that many fractures which we now see routinely may not fit into this classification, the Lauge-Hansen classification is still worth preserving. It clarifies some, if not most deforming forces, allows us to understand the ankle injury in a three-dimensional concept, both on the medial and lateral sides, and allows an understanding of reduction methods. The limitations in its use are the lack of prognostication ability, the fact that most reductions are now done open, and the recognition of some transitional and posterior malleolar injuries unclassifiable by it. Not being alphanumeric is another disadvantage in the computer age. Nevertheless, it is an important landmark in the history of orthopedics, and in the development of our understanding of ankle fractures. Even in 2017, it is too important a piece of work to be discarded, and modern orthopedic students are encouraged to gain an understanding of this classification system, and to combine it with the newer ones to get an overall picture of the ankle injury.
\end{abstract}

Keywords: Ankle fractures, Danis-Weber classification, Fracture classification, Lauge-Hansen, Malleoli.

How to cite this article: Dhillon MS, Kumar L, Sharma S, Mehta N. The Lauge-Hansen Classification for Ankle Fractures: Is it Relevant in 2017? J Foot Ankle Surg (Asia-Pacific) 2017;4(2):53-56.

Source of support: Nil

Conflict of interest: None

\section{INTRODUCTION}

Fractures of the ankle joint are among the commonest fractures in adults, with an incidence of up to 174 cases per 100,000 persons per year ${ }^{1}$ accounting for $9 \%$ of all fractures, ${ }^{2}$ representing a significant portion of the trauma workload. ${ }^{3}$ Around $2 \%$ of ankle fractures are open fractures. ${ }^{4}$ Ankle fractures have a bimodal age distribution,

\footnotetext{
${ }^{1}$ Professor and Head, ${ }^{2,4}$ Senior Resident, ${ }^{3}$ Assistant Professor

${ }^{1-4}$ Department of Orthopaedics, Postgraduate Institute of Medical Education and Research, Chandigarh, India

Corresponding Author: Siddhartha Sharma, Assistant Professor, Department of Orthopaedics, Postgraduate Institute of Medical Education and Research, Chandigarh, India, Phone: +9199988793537, e-mail: sids82@gmail.com
}

with peaks in younger males and older females. ${ }^{5}$ Since the mid-1900s, this rate has increased significantly in many industrialized countries, most likely due to growth in the number of people involved in athletics and in the size of the elderly population.

The vast majority of ankle fractures are malleolar fractures: 60 to $70 \%$ occur as unimalleolar fractures, 15 to $20 \%$ as bimalleolar fractures, and 7 to $12 \%$ as trimalleolar fractures. ${ }^{4,6,7}$ There are similar fracture rates overall between women and men, but men have a higher rate as young adults, while women have higher rates in the 50- to 70-year age group. ${ }^{4,6,7}$

Ankle fractures are produced by a combination of deforming forces including rotation, angulation, axial loading, and translation. These forces are applied to a body in motion, and the forces transmitted across the ankle joint along various vectors change with various velocities. Knowing the precise mechanism of ankle fractures is important because it helps surgeons assess the fracture pattern and soft tissues to determine the sequence of the injury and planning of treatment. Identifying a fracture and classifying the type of injury enable diagnosis of otherwise occult ligament injuries. One of the most popular classifications for ankle fractures is the Lauge-Hansen classification. This article presents a critical review of the Lauge-Hansen classification and its applicability in the current scenario.

\section{ANKLE FRACTURE CLASSIFICATIONS}

Sir Percivall Pott developed the first classification system for ankle fractures, ${ }^{8}$ which was based on the number of malleoli involved, thus dividing injuries into unimalleolar, bimalleolar, or trimalleolar fractures. This classification system just gave a basic anatomical description of the fracture with no relevance to its mechanism of injury or stability of fracture.

Two other common classification systems used for ankle fracture were Danis-Weber system and LaugeHansen. The location of the distal fibular fracture in relation to the syndesmosis of the ankle joint was based on the Danis-Weber system, ${ }^{9}$ with they being classified as type I-infra-syndesmotic, type II-trans-syndesmotic, or type III-supra-syndesmotic injury (Table 1).

In the 1950s, Niels Lauge-Hansen (Fig. 1), a Danish physician, ${ }^{10}$ carried out a series of cadaver studies trying 
Table 1: Danis-Weber classification of ankle fractures

\begin{tabular}{ll}
\hline Type & Description \\
\hline A & $\begin{array}{l}\text { Fracture below the syndesmosis. Avulsion injuries } \\
\text { associated frequently with oblique or vertical medial } \\
\text { malleolar fractures. }\end{array}$ \\
B $\quad \begin{array}{l}\text { Fracture begins at joint level and extends proximally } \\
\text { in an oblique fashion. When accompanied by medial } \\
\text { malleolus fracture or with deltoid ligament rupture } \\
\text { (correlates with SER injury), the ankle is considered } \\
\text { unstable }\end{array}$ \\
$\begin{array}{l}\text { Fractures above the joint line, generally with } \\
\text { syndesmotic injury. Can be associated with transverse } \\
\text { avulsion medial malleolus fracture or deltoid ligament } \\
\text { rupture (includes some pronation-abduction and } \\
\text { pronation-external rotation fractures) }\end{array}$ \\
\hline
\end{tabular}

to find an insight to the pattern of ankle injuries, which in turn gave rise to the mechanism-based classification system of ankle injuries. Freshly amputated specimens were used for the study after they were fixed to wooden boards. Four categories and 13 subgroups of fracture pattern were described by him depending on the position of the foot and the direction of the deforming force at the time of injury (Table 2). Lauge-Hansen had reported that ankle fractures followed a definitive characteristic and reproducible pattern of osseous and soft tissue injury covering more than $95 \%$ of all the ankle fractures. Hence, was born his mechanistic classification system which has so far been the most commonly used system for ankle fractures, providing further information about reduction maneuvers needed and stability of the fracture.

For staging and diagnosing the mechanism of injury according to the Lauge-Hansen classification, radiographic interpretation is required, which aids in further

Table 2: The Lauge-Hansen classification of ankle injuries

\begin{tabular}{|c|c|}
\hline Type & Description \\
\hline SER & $\begin{array}{l}1 \text { Injury of the anterior inferior tibiofibular ligament } \\
2 \text { Oblique/spiral fracture of the distal fibula } \\
3 \text { Injury of the posterior inferior tibiofibular } \\
\text { ligament or avulsion of the posterior malleolus } \\
4 \text { Medial malleolus fracture or injury to the deltoid } \\
\text { ligament }\end{array}$ \\
\hline $\begin{array}{l}\text { Supination- } \\
\text { adduction }\end{array}$ & $\begin{array}{l}1 \text { Transverse fracture of the distal fibula } \\
2 \text { Vertical fracture of the medial malleolus }\end{array}$ \\
\hline $\begin{array}{l}\text { Pronation- } \\
\text { external } \\
\text { rotation }\end{array}$ & $\begin{array}{l}1 \text { Medial malleolus fracture or injury to the deltoid } \\
\text { ligament } \\
2 \text { Injury of the anterior inferior tibiofibular ligament } \\
3 \text { Oblique/spiral fracture of the fibula proximal to } \\
\text { the tibial plafond } \\
4 \text { Injury of the posterior inferior tibiofibular } \\
\text { ligament or avulsion of the posterior malleolus }\end{array}$ \\
\hline $\begin{array}{l}\text { Pronation- } \\
\text { abduction }\end{array}$ & $\begin{array}{l}1 \text { Medial malleolus fracture or injury to the deltoid } \\
\text { ligament } \\
2 \text { Injury of the anterior inferior tibiofibular ligament } \\
3 \text { Transverse or comminuted fracture of the fibula } \\
\text { proximal to the tibial plafond }\end{array}$ \\
\hline
\end{tabular}

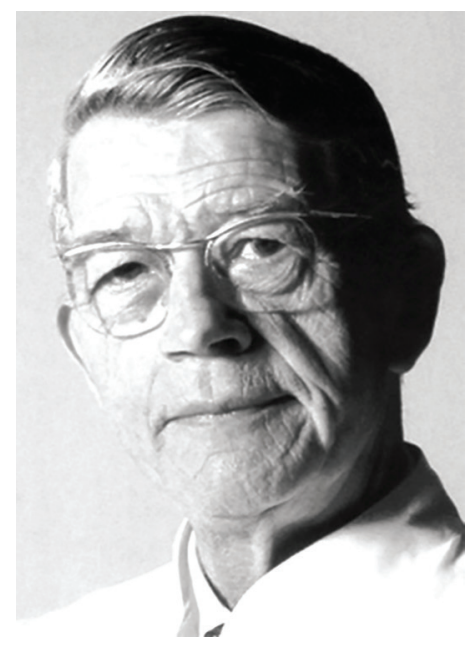

Fig. 1: Sir Niels Lauge-Hansen (image downloaded from http://www. mapfre.com/fundacion/html/revistas/trauma/v25n4/eponimos.html)

treatment of the ankle fracture. Many radiologists prefer to describe rather than classify ankle injuries based on the Lauge-Hansen classification system, a possible reason being that it is complex and cumbersome for even the experienced radiologist to use. ${ }^{11,12}$

The AO/OTA system uses a systematic approach with alphanumeric coding and classifies all long bone fractures based on location, fracture pattern, comminution of fracture fragments, extent of fracture, and topography. According to the AO/OTA classification, ankle fractures are classified into three groups: Infra-syndesmotic (correlating to Danis-Weber type I injuries), trans-syndesmotic (correlating to Danis-Weber type II injuries), or suprasyndesmotic (correlating to Danis-Weber type III injuries), with further subgrouping of the fracture pattern based on presence or absence of posterior or medial malleolar injuries. ${ }^{13}$ It is of importance to note that the medial and posterior structures of the ankle complex are completely ignored in the Danis-Weber classification which is primarily based on the level of syndesmotic injury.

\section{SHORTCOMINGS OF THE LAUGE-HANSEN CLASSIFICATION}

This half a century old mechanistic classification system has been under debate and a topic of controversy from the orthopedic community for the last couple of years. Issues raised over the last few years were inability of recent modern studies to reproduce the mechanism and sequence of injuries described originally with very low reproducibility rates quoted by few authors ${ }^{14-22}$ and inability to accommodate some fracture patterns in his classification, bringing this classification system under constant scrutiny among the orthopedic world. Although the Lauge-Hansen system describes many fracture patterns, some fractures are more complicated and do not fit into a definitive pattern. ${ }^{14}$ Another pitfall of this system is that 
it was originally described in cadavers, with simulations of the traumatic mechanisms, a method, i.e., not always as precise as studying the mechanisms in live patients. ${ }^{10}$

$Y_{d e} e^{15}$ in his study emphasized that the classification of Lauge-Hansen ${ }^{10}$ gives a very exact description of ankle fractures. However, studies carried out by Lindsjo ${ }^{16}$ and Nielsen et $\mathrm{al}^{17}$ showed a high interobserver variation.

Haraguchi and Armiger ${ }^{18}$ challenged the importance of foot positioning in ankle fractures. Twenty-three cadaver ankles were subjected to a pronation-external rotation force, with and without an additional lateral force. Their results demonstrated that both short oblique fractures [consistent with the supination and external rotation (SER) pattern] and high fibular fractures could be produced and that this depended on whether the foot was subjected to an additional lateral force or not at the time of injury.

Michelson et $\mathrm{al}^{19}$ utilized 30 cadaver specimens in an attempt to duplicate Lauge-Hansen's findings for the SER mechanism. The feet were supinated to $25^{\circ}$ and an external rotation force was applied with a neutral ankle position, with $25^{\circ}$ of plantar flexion, and with $10^{\circ}$ to $15^{\circ}$ of dorsiflexion. Pure SER with the ankle in any of these positions did not result in the SER fracture pattern. However, when combined with an applied lateral force and valgus repositioning, four of five experiments produced an oblique fibular fracture, and five of five produced the characteristic stage II injury with additional dorsiflexion in this position.

This arguable debate on the importance of foot positioning was further questioned when Stiehl et $\mathrm{al}^{20}$ in their study found little correspondence between foot position and injury patterns. They had subjected 26 ankle specimens to an external rotation force, and noted minimal correlation between foot position and type of injury that occurs. Interestingly, in their study, they found a marked difference in injury patterns between specimens from female and male cadavers. Female specimens tended to sustain a transverse fibular fracture without syndesmotic or deltoid injury in almost $45 \%$ of cases. They were also able to produce 17 oblique distal fibular fractures, and only 13 of these cases had evidence of an associated injury of the anterior inferior tibiofibular ligament. ${ }^{20}$

Magnetic resonance imaging (MRI)-based studies were carried out by Gardener et $\mathrm{al}^{21}$ to find out the association and reproducibility between mechanism of injury and associated injuries as described in the Lauge-Hansen classification. A total of 49 ankle fractures were evaluated in this study with both radiographic and MRI studies. Experienced orthopedic traumatologists and musculoskeletal radiologists were involved in the study to designate the fractures into the appropriate classification, and for diagnosing the associated ligamentous injuries; $17 \%$ of all the fractures in this study were not classifiable by the Lauge-Hansen classification. Of those patterns that were classifiable, $53 \%$ had a ligamentous injury or fracture that did not coincide with the Lauge-Hansen injury patterns.

In a study carried out by Kwon et al, ${ }^{22}$ the LaugeHansen system was found to be accurate in only $58 \%$ of injuries caused by the supination-adduction and pronation-external rotation injury mechanisms. In a follow-up study carried out by the same authors, ${ }^{23}$ they found a $65 \%$ accuracy, predicting fracture patterns based on the deforming injury mechanism. It is noteworthy that these studies utilized injury videos obtained from the web site www.YouTube.com for carrying out the study, but the authors in this study only used SER mechanism, and other mechanisms were not examined.

In the 21st century, many things have changed. Some points are noteworthy of consideration when the validity of these classification systems is evaluated, especially after a span of so many years since its introduction, and a shift of treatment modalities from closed reduction to an almost mandatory open reduction and stable fixation.

In Lauge-Hansen's description of his original technique, all application of forces and manipulations was done by hand with an uncontrolled magnitude of force to a fixed foot. ${ }^{10}$ In this modern era of orthopedic advancement, studies have shown that the testing parameters enforced 50 years ago were not only not of standard precision, but they also fail to reproduce accurately the in vivo forces which are actually experienced by a patient while sustaining an ankle fracture.

Additionally, recent studies have shown that a small percentage of ankle fractures, such as isolated fractures of the posterior tibial margin, do not fit into the LaugeHansen classification. ${ }^{15,21}$

On the contrary, the Danis-Weber system is based on the radiographic appearance of fracture pattern and the level of the fibular injury; this does not consider the mechanism or the position of the foot at the time of injury (which was based on the Lauge-Hansen system), and which has been debated to be imprecise in this modern time. The newer system classifies the instability perceived in the ankle, and allows the surgeon to plan for stabilization options. However, it is important to note that the medial side of the ankle, which forms one of the pillars of ankle stability and function, has been completely ignored here. It is thus clear that both the ankle classification systems used in modern orthopedics fail to incorporate the distal tibial plafond fractures, which form a part of the ankle joint, and are being seen more frequently. These so-called transitional fractures with inherent instability and more articular damage need to also be looked at. Additionally, both the systems were not designed to incorporate management of open fractures of the ankle joint, which is a segment of the ankle fracture population which is growing significantly. 


\section{CONCLUSION}

The Lauge-Hansen classification is pioneering work on ankle fractures carried out on cadaveric specimens, where the pathobiomechanics were replicated using manual force by hand; this always had the element of imprecision, and considered the position of the foot and direction of the deforming force as paramount to deduce the mechanics of fracture pattern. This was important 50 years ago, when reductions of the ankle needed to be done by closed methods, and reversing the deforming forces was the key to reduction accuracy.

Methodological difficulties in carrying out this original work and failure of recent studies to simulate the same sequence of fracture pattern, by both biomechanical and radiographic means, challenge the validity of this classification among the orthopedic community; its present-day usage becomes limited as most reductions of displaced fractures are done by open means. Additional factors that further question its existence include poor interobserver reliability, lack of prognostic prediction, and realization that atypical fracture patterns are being seen, which are not covered under this classification system.

Despite the drawbacks enumerated by numerous studies, this classification system remains the most commonly used and taught classification of ankle fractures; it is the only classification system which attempts to define the pathomechanics of ankle fractures, and thus retains its importance. In the absence of another comprehensive mechanism-based fracture classification, we believe that it still remains relevant. One of the biggest drawbacks is the fact that it cannot be computer coded, a mandatory requirement of modern medicine. Nevertheless, more studies are needed to refine and improve on the shortcomings of this classification. One way to do this could be using finite element analysis, which can simulate a wide variety of injury forces. The ideal situation today is to probably use both the existing classifications, one to understand injury mechanics and the other to define treatment protocols and prognosticate outcomes. Despite naysayers, the Lauge-Hansen classification needs to be understood by all students of modern orthopedics, even if just to realize how our understanding of this complex fracture has evolved.

\section{REFERENCES}

1. Kannus $P$, Palvanen $M$, Niemi S, Parkkari J, Järvinen M. Increasing number and incidence of low-trauma ankle fractures in elderly people: Finnish statistics during 1970-2000 and projections for the future. Bone 2002 Sep; 31(3):430-433.

2. Court-Brown CM, Caesar B. Epidemiology of adult fractures: a review. Injury 2006 Aug;37(8):691-697.

3. Bugler KE, White TO, Thordarson DB. Focus on ankle fractures. J Bone Joint Surg 2012;94:1107-1112.

4. Court-Brown CM, McBirnie J, Wilson G. Adult ankle fractures-an increasing problem? Acta Orthop Scand 1998 Feb;69(1):43-47.
5. Donken CC, Al-Khateeb H, Verhofstad MH, van Laarhoven CJ. Surgical versus conservative interventions for treating ankle fractures in adults. Cochrane Database Syst Rev 2012 Aug;8:CD008470.

6. Daly PJ, Fitzgerald RH Jr, Melton LJ, Ilstrup DM. Epidemiology of ankle fractures in Rochester, Minnesota. Acta Orthop Scand 1987 Oct;58(5):539-544.

7. Jensen SL, Andresen BK, Mencke S, Nielsen PT. Epidemiology of ankle fractures. A prospective population-based study of 212 cases in Aalborg, Denmark. Acta Orthop Scand 1998 Feb;69(1):48-50.

8. Pott P. Some few general remarks on fractures and dislocations: 1758. Clin Orthop Relat Res 2007 May;458:40-41.

9. Danis, R. Les fractures malleolaires. In: Danis R, editor. Theorie et Pratique de l'Osteosynthese. Paris: Masson; 1949. p. 133-165.

10. Lauge-Hansen N. Fractures of the ankle: II. Combined experimental-surgical and experimental-roentgenologic investigations. Arch Surg 1950 May;60(5):957-985.

11. Milner CE, Soames RW. Anatomy of the collateral ligaments of the human ankle joint. Foot Ankle Int 1998 Nov;19(11): 757-760.

12. Mengiardi B, Pfirrmann CW, Vienne P, Hodler J, Zanetti M. Medial collateral ligament complex of the ankle: MR appearance in asymptomatic subjects. Radiology 2007 Mar; 242(3): 817-824.

13. Müller, ME.; Nazarian, S.; Koch, P.; Schatzker, J. The comprehensive classification of fractures of long bones. Berlin: Springer-Verlag; 1990. p. 148-191.

14. Hermans JJ, Beumer A, Mulder PG. Ankle stress test for predicting the need for surgical fixation of isolated fibular fractures: statistical analysis. J Bone Joint Surg Am 2005 Aug; 87(8):1885-1886.

15. Yde J. The Lauge-Hansen classification of malleolar fractures. Acta Orthop Scand 1980 Feb; 51(1):181-192.

16. Lindsjö U. Classification of ankle fractures: the Lauge-Hansen or A0 system? Clin Orthop 1985 Oct;199:12-16.

17. Nielsen JØ, Dons-Jensen H, Sørensen HT. Lauge-Hansen classification of malleolar fractures. An assessment of the reproducibility in I18 cases. Acta Orthop Scand 1990;61(5): 385-387.

18. Haraguchi N, Armiger RS. A new interpretation of the mechanism of ankle fracture. J Bone Joint Surg Am 2009 Apr;91(4):821-829.

19. Michelson J, Solocoff D, Waldman B, Kendell K, Ahn U. Ankle fractures: the Lauge-Hansen classification revisited. Clin Orthop Relat Res 1997 Dec; 345:198-205.

20. Stiehl JB, Skrade DA, Johnson RP. Experimentally produced ankle fractures in autopsy specimens. Clin Orthop Relat Res 1992 Dec;285:244-249.

21. Gardner MJ, Demetrakopoulos D, Briggs SM, Helfet DL, Lorich DG. The ability of the Lauge-Hansen classification to predict ligament injury and mechanism in ankle fractures: an MRI study. J Orthop Trauma 2006 Apr;20(4):267-272.

22. Kwon JY, Chacko AT, Kadzielski JJ, Appleton PT, Rodriguez EK. A novel methodology for the study of injury mechanism: ankle fracture analysis using injury videos posted on YouTube.com. J Orthop Trauma 2010 Aug;24(8):477-482.

23. Rodriguez EK, Kwon JY, Herder LM, Appleton PT. Correlation of AO and Lauge-Hansen classification systems for ankle fractures to the mechanism of injury. Foot Ankle Int 2013 Nov;34(11):1516-1520. 